\title{
Clinical differences of Helicobacter pylori infection in children
}

\author{
Barbara M. Iwańczak ${ }^{1, A-F}$, Anna M. Buchner, B-F, Franciszek Iwańczak ${ }^{1, B-F}$ \\ ${ }^{1}$ Department of Pediatrics, Gastroenterology and Nutrition, Wroclaw Medical University, Poland \\ ${ }^{2}$ Division of Gastroenterology, University of Pennsylvania, Philadelphia, USA \\ A - research concept and design; $\mathrm{B}$ - collection and/or assembly of data; $\mathrm{C}$ - data analysis and interpretation; \\ $\mathrm{D}$ - writing the article; $\mathrm{E}$ - critical revision of the article; $\mathrm{F}$ - final approval of article
}

Address for correspondence

Barbara Iwańczak

E-mail: barbara@iwanczak.com

Funding sources

None declared

Conflict of interest

None declared

Received on July 8, 2015

Revised on October 27, 2015

Accepted on November 13, 2015

\begin{abstract}
Helicobacter pylori infection is widely spread all over the world. The prevalence of $H$. pylori infection in the world varies and depends on numerous factors such as age, ethnicity, geographical and socioeconomic status. Humans have been in a symbiotic relationship with this bacterium for thousands of years. However 10-20\% of people infected with H. pylori are likely to develop gastroduodenal diseases such as peptic ulcer disease, iron deficiency anemia, gastric mucosal atrophy, metaplasia, dysplasia, MALT lymphoma, or gastric adenocarcinoma. Most of these diseases develop as the infection progresses and they are likely to occur later in life among the elderly. In the following years, the use of modern molecular techniques has led to the discovery of new Helicobacter strains and their genotypic differentiation. Newly discovered Helicobacter microorganisms can colonize human gastrointestinal tract and bile ducts. This article summarizes the distinct features of $H$. pylori infection in children including its prevalence, clinical manifestation, indications for treatment and recommended schemes of eradication.
\end{abstract}

Key words: children, treatment, epidemiology, Helicobacter pylori, clinical presentation

DOI

10.17219/acem/60581

\section{Copyright}

Copyright by Author(s)

This is an article distributed under the terms of the

Creative Commons Attribution Non-Commercial License

(http://creativecommons.org/licenses/by-nc-nd/4.0/) 
H. pylori infection is the most common bacterial infection in the world and has a long history of maintaining a symbiotic relationship with people. Genetic studies suggest that $H$. pylori colonization in humans has occurred already 58,000 years ago and was initiated in east Africa resulting in its subsequent spread. ${ }^{1}$ The discovery of $H$. pylori by Warren and Marshall in 1982 in patients with chronic gastritis and peptic ulcer disease has contributed to further major advances in $H$. pylori research. $^{2-6}$ In 1994, the World Health Organization classified $H$. pylori as a group 1 carcinogen for gastric adenocarcinoma. ${ }^{6}$ In the following years, the use of modern molecular techniques has led to the discovery of new Helicobacter strains and their genotypic differentiation. Newly discovered Helicobacter microorganisms, such as $H$. heilmannii, $H$. mustellae, $H$. felis, $H$. hepaticus, $H$. bilis, and $H$. pullorum can colonize human gastrointestinal tract and bile ducts. ${ }^{7-11}$

\section{Epidemiology of $H$. pylori infection}

The prevalence of $H$. pylori infection in the world varies and depends on numerous factors such as age, ethnicity, geographical and socioeconomic status. ${ }^{12-18} \mathrm{H}$. pylori infection is the most prevalent in developing countries of Africa, South America and Asia; whereas highly developed countries are the least infected. Goh et al. assessed the prevalence of $H$. pylori infection based on 31 publications from the Asia-Pacific region, Africa, Europe, and North and South America. ${ }^{15}$ H. pylori serological tests were the most commonly used methods in determining the infection. The authors reported the high infection rates in the healthy population of South Korea (50.8\%), Shanghai (71.7\%), South Africa (66.1\%), and the lowest rates in the the USA (7.5\%) and Australia (15.5\%), respectively. In developing countries, $H$. pylori infection is markedly more prevalent at a younger age than it is in developed countries. ${ }^{13}$ According to Hunt et al., the prevalence of $H$. pylori infection in Ethiopian children, aged 2-4 years, was $48 \%$, while in adults was over $95 \%$; in Nigeria the prevalence of infection in children aged 5-9 years was $82 \%$, while in adults ranged between $70-$ 90\%; in Mexico in children aged 5-9 years was 43\%, and in adults ranged from 70 to $90 \% .{ }^{13}$ On the other hand, the H. pylori infection in children aged 5-18 years in Canada was reported to be $7.1 \%$, whereas among adults aged 50-80 years to $23.1 \%$ respectively. In Europe, the most infected children were 1-17 years old and came from Bulgaria (61.7\%), whereas the least infected children were from the Netherlands (1.2\%). The epidemiological studies on $H$. pylori infection in Poland examined H. pylori seroprevalence and reported that $32.0 \%$ of children between 6 months and 18 years of age were infected, as compared to $84.19 \%$ of adults aged $19-89$ years $(\mathrm{p}<0.0001) .{ }^{14}$ In addition, it should be noted that the prevalence of infection in children aged $2-3$ years was as high as $26.4 \% .{ }^{14}$ Rowland et al. studied the prevalence of $H$. pylori infection in children in terms of age and infection risk factors. ${ }^{17}$ The study included 327 children between the age of 24 to 48 months. H. pylori infection in children, parents and siblings was diagnosed using the carbon 13-urea breath test. Children without $H$. pylori infection were examined each year for 4 subsequent years with the urea breath test. Out of 327 children 28 were infected with $H$. pylori; and the average age of infected patients was 32.78 months. The rate of new infections per 100 persons a year in children aged 3-4 years were 4.20, whereas in children aged $4-5$ years 2.07 . Only 1 child aged $5-8$ years was infected. This child's mother and older siblings were infected with $H$. pylori, and the child itself had been bottle-fed after 24 months of age, which was also considered a risk factor for infection. The results of these studies confirm that $H$. pylori infection occurs mostly in the first years of children's life and the risk of infection decreases when the children are over 5 years of age.

The most common risk factors of $H$. pylori infection in children were poor socio-economic and hygienic conditions and high population density. ${ }^{14-16,19}$ According to Porras et al., the presence of 3 or more children in the family in addition to the lack of running water and sanitation, increases the risk of infection. ${ }^{19}$ Moreover, Bostos et al., in their meta-analysis, demonstrated that children attending childcare facilities are more prone to frequent infections with $H$. pylori. ${ }^{20}$ On the other hand, the main reasons for the presence of $H$. pylori infection in adults are socio-economic conditions, the level of education, smoking, alcohol drinking, and the lack of proper hygiene habits. ${ }^{14}$ In the recent decades, the study of $H . p y$ lori infection rate has shown a decrease in the number of people infected. This is related to the improvement of socio-economic conditions, and frequent antibiotic treatment administered to cure other diseases. ${ }^{21-24}$

Kosunen et al., in a Finnish study, showed a fall in the seroprevalence rate from 56\% to 31\% between 1973 and $1994 .{ }^{22}$ In addition, the prevalence of the pathogenic cagA(+) strains significantly decreased (34\% to $8 \%$, $\mathrm{p}<0.001$ ) more than in the case of cagA(-) strains (from $12 \%$ to $6 \%)$. The estimated seroconversion rate amounted to $0.4 \%$, and the reversion rate to $0.13 \%$ per year. ${ }^{23}$ Andreasson et al., in the prospective study carried out in Sweden, proved that for 23 years (1989-2012) the seroprevalence significantly fell from $38 \%$ to $16 \%$ (OR: 0.25 ; 95\% CI: $0.11-0.59, \mathrm{p}=0.001$, per decade). ${ }^{24}$ The results from these studies confirm the cohort effect in developed countries. However, Rosenstock et al., in a Danish study, did not report a fall in the seroprevalence of $H$. $p y$ lori infection in 1983-1994. ${ }^{25}$ In this study, the number of people infected with $H$. pylori was stable and ranged from $24.7 \%$ to $24.5 \%$. It should be, however, noted that the reported $H$. pylori infection rate also depends on the detection methods. Serological methods give falsely higher 
rates compared to the urea breath test or to the culture of $H$. pylori from stool samples as the methods can be related to $H$. pylori antibodies, presence for several months after eradication.

The incidence of pathogenic $H$. pylori strains cagA(+) in children has been also analyzed in various studies. ${ }^{5,9,26,27}$ The occurrence of pathogenic $H$. pylori strains cagA(+) was more frequently reported in children than in adults (77.0\% vs 63.8\%, p < 0.001). ${ }^{27}$ Significant differences in the percentage of cagA(+) strains in particular studies regions of Poland have been also confirmed ranging from $40.6 \%$ to $91.6 \% .{ }^{27}$ The most frequently observed genotypes in children were cagA(+) s1m1 (34.0\%), and cagA(+) s1m2 (31.9\%), whereas in adults cagA $(+) \mathrm{s} 1 \mathrm{~m} 2$ (31.0\%) and cagA(+) s1m1 (23.1\%). Statistically significant difference was reported between the prevalence of cagA(+) s1m1 in children and in adults $(34.0 \%$ vs $23.1 \%, \mathrm{p}<0.0279) .{ }^{27}$ However, in children $H$. pylori cagA(-) genotype was $23.0 \%$, and in adults $36.2 \%(\mathrm{p}<0.001)$.

\section{Infection transmission and reinfection}

Urita et al. evaluated the potential relationship between $H$. pylori prevalence among children and grandparents in three-generation households in a Japanese rural town. ${ }^{28}$ Based on this study, $H$. pylori spread in a 3-generation households occur not only through mother to child transmission but also through the grandmother to child route. Interestingly, having an infected father or grandfather was not a significant predictor for the infection being present in children.

The spontaneous resolution of infection or the infection with new strains primarily after eradication have been reported in people infected with $H$. pylori. ${ }^{29,30}$ Vanderpas et al. reported that the reinfection after eradication for the period of 5 years amounted to $48.6 \%$, and new infections that occurred in the period of 10 years in previously negative people amounted to $38.7 \% .^{30}$ The risk of acquiring the infection was fourfold higher in non-European than in European children ( $\mathrm{p}<0.001)$. Other authors have also reported $H$. pylori seroconversion. Kumagai et al., in longitudinal cohort studies in children and adults between 1986 and 1997, reported H. pylori seroconversion rates were $1.1 \%$ and $1.0 \%$ per year for children and adults, respectively. ${ }^{31}$

\section{Clinical presentation}

H. pylori colonizes the gastric mucosa, leading to chronic inflammation in all infected humans, including children and adolescents. However, the majority of infected people have no statistically significant symptoms and remain free of symptoms throughout their lives. ${ }^{14}$
Approximately 10-20\% of people with $H$. pylori infection may develop stomach ulcers and/or duodenal ulcers, gastric mucosal atrophy, metaplasia, dysplasia, lymphoma, or gastric adenocarcinoma. ${ }^{5,32-38}$ The specific presentation depends on the virulence features of the bacteria, host characteristics and environmental factors. Many studies have shown that the most virulent genotypes of $H$. pylori are cagA(+), vacA (+). The recently published large multicenter study analyzing genotypic and clinical differences of H.pylori infection in the Polish population demonstrated that the presence of cagA(+) s1m2 and cag $\mathrm{A}(+)$ s1m1 strains is found more frequently in children than in adults. ${ }^{27}$ Genotype cagA(+) s1m1 has been detected statistically more often in children than in adults $(34.0 \%$ vs $23.1 \%, \mathrm{p}=0.02)$. However, $H$. pylori cagA(-) s2m2 strain occurred more frequently in adults than in children $(27.1 \%$ vs $14 \%, \mathrm{p}=0.003)$. There was no effect of $H$. pylori infection on clinical symptoms such as nausea, regurgitation, vomiting, heartburn and abdominal pain in pediatric population. ${ }^{27}$ In contrast, adults infected with $H$. pylori had more frequent episodes of heartburn and abdominal pain. ${ }^{27}$

Other studies demonstrated that in both children and adults, there is a statistically significant association between the seroprevalence of $H$. pylori and duodenal ulcer disease. ${ }^{14,26}$ Biernat et al. analyzed the relationship between clinical outcomes of infection and the prevalence of $H$. pylori cagA, vacA, ICEA and babA 2 genotypes in 130 children and adolescents aged $4-18$ years. ${ }^{26}$ The authors demonstrated a statistically significant association between the presence of cagA gene and duodenal ulcer ( $\mathrm{p}<0.05$ ) whereas vacAs $1 / \mathrm{m} 1$ genotype of $H$. pylori was frequent in children with gastritis and gastroesophageal reflux disease (GERD). In children with dyspepsia and GERD, vacAs $2 / \operatorname{cagA}(-) /$ iceA1(+)/babA2(-) were frequent. Bontems et al. in a multicenter, prospective study enrolling 124 children from 11 European centers evaluated the risk factors for peptic ulcer and/or erosion of the stomach or duodenum. ${ }^{39}$ The investigators demonstrated that $H$. pylori infection is the risk factor only for the occurrence of erosions and duodenal ulcers. In other studies the seroprevalence of $H$. pylori was more frequently observed in children than in adults. ${ }^{27,40}$ The granulation of gastric mucosa associated with the lymphoid follicles hypertrophy and the thickening of the gastric mucosa folds were also seen. However, gastric mucosal atrophy, intestinal metaplasia and dysplasia occurred less frequently in children than in adults. ${ }^{27,40}$

De Sablet et al. have reported that $H$. pylori strain of European origin as compared to African origin was strongly predictive of the increased risk of precancerous gastric lesions, even in the low risk region. ${ }^{37}$ Gonzalez et al. analyzed the gastric precancerous lesions in 312 patients. ${ }^{38}$ The median follow-up was 12.8 years. The authors demonstrated advanced premalignant lesions in patients infected with $H$. pylori cagA(+) vacAs1/m1 strains 
in comparison to patients infected with $\operatorname{cagA}(-)$ vacAs $2 \mathrm{~m} 2$ strains. This led to the conclusion that genotyping $H$. pylori strains may be useful in identifying higher risk patients infected with virulent strains of $H$. pylori that require more intensive surveillance.

\section{Extra-intestinal manifestations}

Many studies investigated the relationship between infection with $H$. pylori and iron-deficiency anemia, B12 deficiency, acute idiopathic thrombocytopenic purpura (ITP), and allergic diseases. ${ }^{41-46}$ Infected children are less susceptible to wheezing, allergic rhinitis and skin allergies. ${ }^{41}$ Several meta-analyses have confirmed the relationship between unexplained iron deficiency anemia and infection with $H$. pylori, both in children and adults. ${ }^{42-44}$ Harris et al., in a prospective study, have demonstrated the correlation between $H$. pylori infection associated hypochlorhydia and the development of iron deficiency in 123 children. ${ }^{45} \mathrm{Lu}$ et al., evaluated the role of $H$. pylori in the pathogenesis of acute idiopathic thrombocytopenic purpura (ITP) and have shown that the prevalence of pediatric infections with $H$. pylori and controls ITP group were similar and amounted to $41.30 \%$ and $35.71 \%$, respectively. ${ }^{47}$ No difference was found between the initial platelet counts and megakaryocytes. Xiong et al., in a meta-analysis study, have demonstrated a possible link between $H$. pylori infection in Henoch-Schonlein purpura (HSP) as compared to the control group (49.27\% vs $23.39 \%$ ) in Chinese children. ${ }^{48}$ Eradication of $H$. pylori infection reduced the recurrence of HSP. Wang et al., in a meta-analysis, have evaluated the association between asthma and $H$. pylori infection. ${ }^{49}$ This analysis has shown a weak inverse association between asthma and $H$. pylori infection in children and adults. In contrast, Karimi et al. have not confirmed the relationship between $H$. pylori infection and asthma in children. ${ }^{50}$

\section{Diagnosis of $H$. pylori infection in children}

According to the guidelines from the European Society of Pediatric Gastroenterology, Hepatology and Nutrition (ESPGHAN) and the North American Society for Pediatric Gastroenterology, Hepatology and Nutrition (NASPGHAN) diagnostic testing for $H$. pylori infection in children should be performed only when symptoms such as vomiting, persistent abdominal pain, and gastrointestinal bleeding can justify the gastroduodenoscopy with biopsy samples for examination. ${ }^{51}$ In such cases it is important to determine the underlying cause of the symptoms and not solely focus on the presence of $H$. pylori infection. If there are no symptoms suggestive of organic disease, a decision whether to conduct diagnostic testing for $H$. pylori infection should be taken individually. Diagnostic testing for $H$. pylori infection may be considered in children with refractory iron-deficiency anemia, and idiopathic thrombocytopenic purpura. ${ }^{51}$ Diagnostic testing for $H$. pylori infection is not recommended in children with functional abdominal pain.

A diagnosis of the infection should be based on invasive tests, i.e., culture, rapid urease test, polymerase chain reaction (PCR), or non-invasive tests, which include the urea breath test (UBT), detection of $H$. pylori antigens in stool or detection of antibodies to H. pylori in serum. ${ }^{13,51-54}$ Diagnostic testing should be carried out at least 2 weeks after the completion of proton pump inhibitors (PPI) therapy, and 4 weeks after antibiotic treatment. The effectiveness of $H$. pylori eradication treatment is most commonly assessed with a non-invasive test, i.e., the urea breath test, or with $H$. pylori antigen stool test 4-8 weeks after eradication therapy. Serological tests measuring antibodies in serum or urine are not recommended for the evaluation of the treatment effectiveness, since antibodies can be present after $H$. pylori eradication for several months. ${ }^{51}$

\section{Recommendations for H. pylori treatment in children}

The main indication for treating $H$. pylori infection in children is peptic ulcer disease. H. pylori eradication should be considered in the case of its prevalence in the esophageal mucosa without peptic ulcer disease. Firstdegree relatives of patients with gastric cancer may be offered the eradication of $H$. pylori. A "test and treat" strategy is not recommended in case of children. ${ }^{51}$

\section{Treatment of $H$. pylori infection in children}

Studies on the effectiveness of $H$. pylori eradication are focused on selecting regimens which aim to achieve the highest eradication rates with the lowest incidence of side effects. The effectiveness of treatment regimens depends on the sensitivity of $H$. pylori strains to drugs used, the duration of the treatment and patients' compliance in taking medication..$^{51,53,54}$ It is recommended that drugs are tailored to the antibiotic susceptibility of $H$. pylori strains in a given region. ${ }^{51,55-57}$ The best results of $H$. pylori eradication are achieved after the first treatment; subsequent treatments with the same antibiotic may be less effective due to the increasing secondary antibioticresistance of $H$. pylori strains. Clarithromycin has the most significant impact on the effectiveness of $H$. pylori eradication, followed by metronidazole. Low-level amoxicillin resistance (4.9-10.8\%) has been reported in China, 
Thailand and Korea; whereas high-level resistance to clarithromycin has been reported in European countries (15-24\%) and in China (37.8\%). ${ }^{51,56-59}$ The prevalence of metronidazole resistance has been even higher. ${ }^{21,51,57-62}$ In Poland, the resistance to clarithromycin depends on the region; in children it was between $9 \%$ and $26 \%$, in adults from $3 \%$ to $27 \%$; the resistance to metronidazole in children was from $16 \%$ to $43 \%$, in adults from $27 \%$ to $52 \% .{ }^{27}$ However, it should be noted that in different countries $H$. pylori antibiotic resistance varies, and depends mainly on the frequency of antibiotics used for treatment of other infections in a given region. ${ }^{21}$

ESPGHAN and NASPGHAN recommend the following regimens in the first-line therapy: ${ }^{51}$

1. PPI (proton pump inhibitor) $1-2 \mathrm{mg} / \mathrm{kg} / \mathrm{day}+$ amoxicillin $(50 \mathrm{mg} / \mathrm{kg} /$ day $)+$ metronidazole $(20 \mathrm{mg} / \mathrm{kg} /$ day $)$ or,

2. PPI + amoxicillin + clarithromycin $(20 \mathrm{mg} / \mathrm{kg} /$ day $)$ if the resistance to $H$. pylori does not exceed $15 \%$ in the region or,

3. Bismuth salts (bismuth subcitrate or subsalicytate) $8 \mathrm{mg} / \mathrm{kg} /$ day + amoxicillin + metronidazole.

The aforementioned medications may be administered in divided doses 2 times a day (with the maximum daily dose for amoxicillin amounting to $2000 \mathrm{mg}, 1000 \mathrm{mg}$ for metronidazole, $1000 \mathrm{mg} /$ day for clarithromycin ) for 10-14 days. ${ }^{51}$ Sequential therapy, which includes dual therapy with PPI and amoxicillin for 5 days, followed by 5 days of triple therapy: PPI with clarithromycin and metronidazole/tinidazole has also been used in the last decade. ${ }^{63-67}$ If $H$.pylori resistance to clarithromycin is high in the given region, PPI therapy in combination with bismuth and two antibiotics is recommended.

In the second-line therapy, if $H$. pylori are not eradicated with clarithromycin, a four-drug regimen with a new antibiotic is recommended. Moreover, determining the clarithromycin-susceptible $H$. pylori isolates is advocated. ${ }^{51}$

\section{Conclusions}

For thousands of years people have lived in symbiosis with $H$. pylori. Only some patients with $H$. pylori infection may develop health issues and life threatening diseases. This depends on the bacterial virulence, host characteristics, and environmental factors. Chronic infections with $H$. pylori can lead to peptic ulcer disease, iron deficiency anemia, MALT lymphoma, or gastric cancer. Children infected with $H$. pylori are less susceptible to wheezing, allergic rhinitis, and other allergic diseases. Indications for eradicating $H$. pylori infection in children are limited to peptic ulcer disease. A "test and treat" strategy does not apply in pediatric patients. Due to the increased $H$. pylori resistance to clarithromycin, its efficacy in $H$. pylori eradication is limited, and antimicrobial sensitivity testing is advocated.

\section{References}

1. Linz B, Balloux F, Moodley $Y$, et al. An African origin for the intimate association between humans and Helicobacter pylori. Nature. 2007;445:915-918.

2. Warren JR. Unidentified curved bacilli on gastric epithelium in active chronic gastritis. Lancet. 1983;1(8336):1273-1275.

3. Marshall BJ, Warren JR. Unidentified curved bacilli in the stomach of patients with gastritis and peptic ulceration. Lancet 1984;1(8390):1311-1315.

4. Peterson WL. Helicobacter pylori and peptic ulcer disease. $N$ Engl J Med. 1991;324:1043-1048.

5. Blaser MJ, Berg DE. Helicobacter pylori genetic diversity and risk of human disease. J Clin Invest. 2001;107:767-773.

6. Schistosomes, liver flukes and Helicobacter pylori: IARC Working Group on the Evaluation of Carcinogenic Risks to Humans: Lyon, 7-14 June 1994. IARC Monogr Eval Carcinog Risks Hum. 1994;61:1-241.

7. Blaser MJ. Heterogenecity of Helicobacter pylori. Eur J Gastroenterol Hepatol. 2012;9(suppl 1):3-6.

8. Biernat M, Gościniak G. Gatunki Helicobacter izolowane z przewodu pokarmowego człowieka. Adv Clin Exp Med. 2006:15;113-120.

9. Gzyl A, Augustynowicz E, Dzierżanowska D, et al. Genotypes of Helicobacter pylori in Polish population. Acta Microbiol Pol. 1999;48:261-275.

10. Iwańczak B, Biernat M, Iwańczak F, Grabińska J, Matusiewicz K, Gościniak G. The clinical aspects of Helicobacter heilmannii infection in children with dyspeptic symptoms. J Physiol Pharmacol. 2012;63:133-136.

11. Moyaert H, Franceschi F, Roccarina D, Ducatelle R, Haesebrouck F, Gasbarrini A. Extragastric manifestations of Helicobacter pylori infection: Other Helicobacters. Helicobacter. 2008;13(suppl 1):47-57.

12. Calvet X, Ramírez Lázaro MJ, Lehours P, Mégraud F. Diagnosis and epidemiology of Helicobacter pylori infection. Helicobacter. 2013;18(suppl 1),5-11.

13. Hunt RH, Xiao SD, Megraud F, et al. World Gastroenterology Organization. Helicobacter pylori in developing countries: World Gastroenterology Organisation Global Guideline. J Gastrointestin Liver Dis. 2011;20:299-304.

14. Łaszewicz W, Iwańczak F, Iwańczak B, Task Force of the Polish Society of Gastroenterology, Task Force of the Polish Society of Gastroenterology. Seroprevalence of Helicobacter pylori infection in Polish children and adults depending on socioeconomic status and living conditions. Adv Med Sci. 2014;59:147-150.

15. Goh KL, Chan WK, Shiota S, Yamaoka Y. Epidemiology of Helicobacter pylori infection and public health implications. Helicobacter. 2011;16(suppl 1):1-9.

16. Jafri W, Yakoob J, Abid S, Sidduqui S, Awan S, Nizami SQ. Helicobacter pylori infection in children: Population-based age-specific prevalence and risk factors in a developing country. Acta Paediatr. 2010:99;279-282.

17. Rowland M, Daly L, Vaughan M, Higgins A, Bourke B, Drumm B. Age-specific incidence of Helicobacter pylori. Gastroenterology. 2006;130:65-72.

18. Strebel K, Rolle-Kampczyk U, Richter M, Kindler A, Richter T, Schlink U. A rigorous small area modelling-study for the Helicobacter pylori epidemiology. Sci Total Environ. 2010;408:3931-3942.

19. Porras C, Nodora J, Sexton R, et al. Epidemiology of Helicobacter pylori infection in six Latin American countries (SWOG Trial S0701). Cancer Causes Control. 2013; 24:209-215.

20. Bastos J, Carreira H, La Vecchia C, Lunet N. Childcare attendance and Helicobacter pylori infection: Systematic review and meta-analysis. Eur J Cancer Prev. 2013;22:311-319.

21. Mégraud F, Coenen S, Versporten A, et al. Helicobacter pylori resistance to antibiotics in Europe and its relationship to antibiotic consumption. Gut. 2013;62:34-42.

22. Kosunen TU, Aromaa A, Knekt $P$, et al. Helicobacter antibodies in 1973 and 1994 in the adult population of Vammala, Finland. Epidemiol Infect. 1997;119;29-34.

23. Perez Perez GI, Salomaa A, Kosunen TU. Evidence that cagA(+) Helicobacter pylori strains are disappearing more rapidly than cagA(-) strains. Gut. 2002;50:295-298.

24. Andreasson A, Talley N, Engstrand L. The prevalence Helicobacter pylori positive in the general population in Sweden has decreased from 38 per cent to 16 per cent since 1989. UEG Journal 2014;(abstract PO 508). 
25. Rosenstock S, Jørgensen T, Andersen L, Bonnevie O. Seroconversion and seroreversion in IgG antibodies to Helicobacter pylori: A serology based prospective cohort study. J Epidemiol Community Health. 2000;54;444-450.

26. Biernat MM, Gościniak G, Iwańczak B. Prevalence of Helicobacter pylori cagA, vacA, iceA, babA2 genotypes in Polish children and adolescents with gastroduodenal disease. Postepy Hig Med Dosw. 2014;22:1015-1021. http://www.phmd.pl/api/files/view/29641.pdf

27. Iwanczak B, Laszewicz W, Iwanczak F, et al. Genotypic and clinical differences of seropositive Helicobacter pylori children and adults in the Polish population. J Physiol Pharmacol 2014;65:801-807.

28. Urita Y, Watanabe T, Kawagoe N, et al. Role of infected grandmothers in transmission of Helicobacter pylori to children in a Japanese rural town. J Paediatr Child Health. 2013:49:394-398.

29. Calvet X, Ramírez Lázaro MJ, Lehours P, Mégraud F. Diagnosis and epidemiology of Helicobacter pylori infection. Helicobacter. 2013;18(suppl 1):5-11.

30. Vanderpas J, Bontems P, Miendje Deyi VY, Cadranel S. Followup of Helicobacter pylori infection in children over two decades (1988-2007): Persistence, relapse and acquisition rates. Epidemiol Infect. 2014;142:767-775.

31. Kumagai T, Malaty HM, Graham DY, et al. Acquisition versus loss of Helicobacter pylori infection in Japan: Results from an 8-year birth cohort study. J Infect Dis. 1998;178:717-721.

32. Backert S, Clyne M. Pathogenesis of Helicobacter pylori infection. Helicobacter. 2011;16:19-25.

33. Konturek PC, Konturek JS, Brzozowski T. Helicobacter pylori infection in gastric carcinogenesis. J Physiol Pharmacol. 2009;60:3-21.

34. Parsonnet J, Friedman GD, Orentreich N, Vogelman M. Risk for gastric cancer in people with cagA positive or cagA negative Helicobacter pylori infection. Gut. 1997;40:297-301.

35. Krzysiek-Maczka G, Targosz A, Ptak-Belowska A, et al. Molecular alterations in fibroblasts exposed to Helicobacter pylori: A missing link in bacterial inflammation progressing into gastric carcinogenesis? J Physiol Pharmacol. 2013;64:77-87.

36. Targosz A, Brzozowski T, Pierzchalski P, et al. Helicobacter pylori promotes apoptosis, activates cyclooxygenase (COX)-2 and inhibits heat shock protein HSP70 in gastric cancer epithelial cells. Inflamm Res. 2012;61:955-966.

37. de Sablet T, Piazuelo MB, Shaffer $C L$, et al. Phylogeographic origin of Helicobacter pylori is a determinant of gastric cancer risk. Gut. 2011;60:1189-1195.

38. González CA, Figueiredo C, Lic CB, et al. Helicobacter pylori cagA and vacA genotypes as predictors of progression of gastric preneoplastic lesions: A long-term follow-up in a high-risk area in Spain. Am J Gastroenterol. 2011;106:867-874

39. Bontems P, Kalach N, Vanderpas J, et al. Helicobacter pylori infection in European children with gastro-duodenal ulcers and erosions. Pediatr Infect Dis J. 2013;32:1324-1329.

40. Asfeldt AM, Steigen SE, Løchen ML, et al. The natural course of Helicobacter pylori infection on endoscopic findings in a population during 17 years of follow-up: The Sørreisa gastrointestinal disorder study. Eur J Epidemiol. 2009;24:649-658.

41. Blaser MJ, Falkow S. What are the consequences of the disappearing human microbiota? Nat Rev Microbiol. 2009;7:887-894.

42. DuBois S, Kearney DJ. Iron-deficiency anemia and Helicobacter pylori infection: A review of the evidence. Am J Gastroenterol. 2005;100:453-459.

43. Muhsen K, Cohen D. Helicobacter pylori infection and iron stores: A systematic review and meta-analysis. Helicobacter. 2008;13:323-340.

44. Qu XH, Huang XL, Xiong $\mathrm{P}$, et al. Does Helicobacter pylori infection play a role in iron deficiency anemia? A meta-analysis. World J Gastroenterol. 2010;16:886-896.

45. Harris PR, Serrano CA, Villagrán A, et al. Helicobacter pylori-associated hypochlorhydria in children, and development of iron deficiency. J Clin Pathol. 2013;66:343-347.

46. Chen Y, Blaser MJ. Helicobacter pylori colonization is inversely associated with childhood asthma. J Infect Dis. 2008;198:553-560.

47. Lu J, Wang CM, Xu ST, et al. Role of Helicobacter pylori infection in the pathogenesis and clinical outcome of childhood acute idiopathic thrombocytopenic purpura. Zhonghua Xue Ye Xue Za Zhi. 2013;34:41-44.
48. Xiong LJ, Tong Y, Wang ZL, Mao M. Is Helicobacter pylori infection associated with Henoch-Schonlein purpura in Chinese children? A meta-analysis. World J Pediatr. 2012;8:301-308.

49. Wang Q, Yu C, Sun Y. The association between asthma and Helicobacter pylori: A meta-analysis. Helicobacter. 2013;18:41-53.

50. Karimi A, Fakhimi-Derakhshan K, Imanzadeh F, Rezaei M, Cavoshzadeh Z, Maham S. Helicobacter pylori infection and pediatric asthma. Iran J Microbiol. 2013:5:132-135.

51. Koletzko S, Jones NL, Goodman KJ, et al. Evidence-based guidelines from ESPGHAN and NASPGHAN for Helicobacter pylori infection in children. J Pediatr Gastroenterol Nutr. 2011;53:230-243.

52. Koletzko S, Konstantopoulos N, Bosman D, et al. Evaluation of a novel monoclonal enzyme immunoassay for detection of Helicobacter pylori antigen in stool from children. Gut. 2003;52:804-806.

53. Guarner J, Kalach N, Elitsur Y, Koletzko S. Helicobacter pylori diagnostic tests in children: Review of the literature from 1999 to 2009. Eur J Pediatr. 2010;169:15-25.

54. Graham DY, Opekun AR, Hammoud F, et al. Studies regarding the mechanism of false negative urea breath tests with proton pump inhibitors. Am J Gastroenterol. 2003;98:1005-1009.

55. Graham DY, Shiotani A. New concepts of resistance in the treatment of Helicobacter pylori infections. Nat Clin Pract Gastroenterol Hepatol. 2008;5:321-331.

56. Malfertheiner P, Megraud F, O'Morain CA, et al. Management of Helicobacter pylori infection - the Maastricht IV: Florence Consensus Report. Gut. 2012;61:646-664.

57. Iwańczak F, Iwańczak B. Treatment of Helicobacter pylori infection in the aspect of increasing antibiotic resistance. Adv Clin Exp Med. 2012;21:671-680.

58. Song Z, Zhou L, Wang Y, et al. A study to explore Hp antibiotic resistance and efficacy of eradication therapy in China (multicenter, nation-wide, randomized, control study). Helicobacter. 2011(16) (suppl 1)(abstract PO 7.05):117.

59. Wu DC, Hsu PI, Wu JY. Sequential and concomitant therapy with four drugs is equally effective for eradication of $H$. pylori infection. Clin Gastroenterol Hepatol. 2010:8;36-41.

60. Moon BS, An B, Kim H, et al. Antibiotic resistance and eradication rate of Helicobacter pylori strains isolated in Korean patients. Helicobacter. 2011;16(suppl 1)(abstract PO 7.13):119.

61. Mégraud F. H. pylori antibiotic resistance: Prevalence, importance and advances in testing. Gut. 2004;53:1374-1384.

62. Martinez Gonzalez B, Papadokos K, Konstontoilaki A, et al. Primary antibiotic resistance and Helicobacter pylori: Virulence factors is there an association? Helicobacter. 2011;16(suppl 1)(abstract PO 7.07):118.

63. Bontems P, Kalach N, Oderda G, et al. Sequential therapy versus tailored triple therapies for Helicobacter pylori infection in children. J Pediatr Gastroenterol Nutr. 2011:53:646-650.

64. Albrecht P, Kotowska M, Szajewska H. Sequential therapy compared with standard triple therapy for Helicobacter pylori eradication in children: A double-blind, randomized, controlled trial. J Pediatr. 2011;159:45-49.

65. Liou JM, Chen CC, Chen MJ, et al. Sequential versus triple therapy for the first-line treatment of Helicobacter pylori: A multicenter, open-label, randomized trial. Lancet. 2013;381:205-213.

66. Fuccio L, Minardi ME, Zagari RM, Grilli D, Magrini N, Bazzoli F. Metaanalysis: Duration of first-line proton-pump inhibitor based triple therapy for Helicobacter pylori eradication. Ann Intern Med. 2007;147:553-562.

67. Schwarzer A, Urruzuno P, Iwańczak B, et al. New effective treatment regimen for children infected with a double-resistant Helicobacter pylori strain. J Pediatr Gastroenterol Nutr. 2011;52;424-428. 